\title{
Very high-cycle fatigue resistance of shot peened high-strength aluminium alloys
}

\author{
M. Benedetti, V. Fontanari \\ Department of Industrial Engineering, University of Trento, Trento (Italy) \\ matteo.benedetti@ing.unitn.it,vigilio.fontanari@ing.unitn.it
}

\author{
M. Bandini \\ Peen Service s.r.l., Bologna (Italy) \\ m.bandini@peenservice.it
}

\begin{abstract}
The present paper is aimed at investigating the effect of shot peening on the very-high cycle fatigue resistance of the Al-7075-T651 alloy. Pulsating bending fatigue tests $(\mathrm{R}=0.05)$ were carried out on smooth samples exploring fatigue lives comprised between $10^{5}$ and $10^{8}$ cycles. Three peening treatments with different intensity were considered to explore different initial residual stress profiles and surface microstructural conditions. An extensive analysis of the residual stress field was carried out by measuring with the X-ray diffraction (XRD) technique the residual stress profile before and at the end of the fatigue tests, so as to investigate the onset of a stabilized residual stress field. Fatigue crack initiation sites have been investigated through scanning electron microscopy (SEM) fractography. The surface morphology modifications induced by shot peening were evaluated using an optical profilometer. The influence of surface finishing on the fatigue resistance was quantified by eliminating the surface roughness in some peened specimens through a tribofinishing treatment.
\end{abstract}

SOMMARIO. Il presente lavoro è incentrato sullo studio dell'effetto della pallinatura sulla resistanza a fatica ad altissimo numero di cicli della lega Al-7075-T651. Prove di fatica a flessione pulsante $(\mathrm{R}=0.05)$ sono state condotte su campioni non intagliati esplorando vite a fatica comprese tra $10^{5}$ e $10^{8}$ cicli. Tre trattamenti di pallinatura di differente intensità sono stati considerati così da esplorare differenti profili di autotensione e condizioni microstrutturali in superficie. Un'analisi estesa del campo di autotensioni è stata condotta misurando mediante diffrattometria a raggi $x$ il profilo di tensioni residue prima e alla fine delle prove di fatica, in modo da studiare le condizioni di rilassamento e stabilizzazione del campo di autotensione. I siti di iniziazione delle fessure di fatica sono stati osservati al microscopio a scansione elettronica. Le modifiche alla morfologia superficiale indotte dalla pallinatura sono state valute mediante un profilometro ottico. L'influenza esercitata della finitura superficiale sulla resistenza a fatica è stata quantificata eliminando in alcuni campioni la rugosità superficiale attraverso un trattamento di tribofinitura.

KEYwORDS. Shot peening; Very high-cycle fatigue; Al-7075-T651; Residual stresses; Tribofinishing.

\section{INTRODUCTION}

luminium alloys are an attractive class of materials for aircraft and automotive industry because of their high specific static strength. In aerospace, aluminium alloys face ever stiffer competition from composites. In the automotive context, more and more engine parts are being made from them. Usually, high static mechanical 
properties are induced in aluminium alloys by dispersion hardening through solution and ageing heat treatments. However, aluminium alloys exhibit poor plain fatigue resistance and high notch fatigue sensitivity. Accordingly, stress raisers, like holes, fillets and grooves, always present in machine parts, are particularly detrimental to the fatigue response of these alloys, thus limiting their use in highly stressed mechanical components characterized by complex shapes. For this reason, aluminium alloys are frequently subjected to shot peening, particularly effective in incrementing the plain and notch fatigue strength of steels and light alloys. The shot peening mainly results in three fatigue related modifications of the surface layers: roughness, residual stresses and work hardening. Clearly, the surface roughening after shot peening is detrimental to the fatigue resistance due to the stress concentration exerted by the surface dimples. In the literature, it is commonly accepted that the improvement of fatigue strength is mainly induced by the introduction of compressive residual stresses in the surface region, responsible for both retarded fatigue crack initiation and lower small crack growth rates $[1,2]$. The role of work hardening on the fatigue response is essentially indirect, since it strongly affects the stability of residual stresses by preventing them from relaxing due to accumulation of plastic deformation [3].

The authors recently studied the effect of three types of shot peening treatments on the plain and notch high-cycle fatigue response of the Al-7075-T651 alloy under reverse bending loading conditions $(\mathrm{R}=-1)$ [4-7]. In particular, it was shown that (i) residual stress relaxation occurs when the superposition between the compressive residual stress and the compressive peak stress produced by reverse bending exceeds the material's cyclic yield stress; (ii) the plain fatigue response is directly correlated with the surface residual stress as successfully predicted using the Sines criterion incorporating the stabilized residual stress field as mean stresses; (iii) gentle peening treatment conducted using small ceramic beads are more effective than more intense treatments employing larger peening media (iv) shot peening reduces the fatigue notch sensitivity; (v) the notch fatigue resistance can be satisfactorily predicted by the Sines fatigue criterion incorporating stabilized residual stresses and combined with a line method based on the critical distance theory to account for the notch sensitivity. However, the current state-of-the-art-knowledge lacks for investigations proving whether the beneficial effect of shot peening is still present in the very-high cycle fatigue regime.

The present paper is aimed at investigating the effect of shot peening on the very-high cycle fatigue resistance of the Al7075-T651 alloy. Pulsating bending fatigue tests $(R=0.05)$ were carried out on smooth samples exploring fatigue lives comprised between $10^{5}$ and $10^{8}$ cycles. Three peening treatments with different intensity were considered to explore different initial residual stress profiles and surface microstructural conditions. An extensive analysis of the residual stress field was carried out by measuring with the X-Ray diffraction (XRD) technique the residual stress profile before and at the end of the fatigue tests, so as to investigate the onset of a stabilized residual stress field. Fatigue crack initiation sites have been investigated through scanning electron microscopy (SEM) fractography. The surface morphology modifications induced by shot peening were evaluated using an optical profilometer. The influence of surface roughness on the fatigue resistance was quantified by eliminating the surface roughness in some peened specimens through a tribofinishing process.

\section{MATERIAL AND EXPERIMENTAL PROCEDURES}

1 he experimentation was performed on the aluminium alloy Al-7075-T651, widely used for aeronautical applications, supplied in the form of $4 \mathrm{~mm}$ thick rolled plate. The bulk material properties were determined on five standard monotonic tensile tests (initial strain rate of $1 \times 10^{-3} \mathrm{~s}^{-1}$ ) performed in the longitudinal orientation. The results, summarized in Tab. 1, show a yield strength higher than $500 \mathrm{MPa}$, combined with a good material ductility (total elongation of $16 \%$ ).

The fatigue characterisation was carried out on prismatic specimens whose geometry, according to the standard ISO 3928, is illustrated in Fig. 1. The microstructure has been tested with the stress axis parallel to the L-direction. The samples present a fillet radius large enough to make any notch fatigue effects negligible.

\begin{tabular}{cccccc}
\hline E & $\sigma_{\mathbf{Y} 0.2}$ & UTS & $\sigma_{\mathbf{F}}$ & T.E. & R.A. \\
{$[\mathrm{GPa}]$} & {$[\mathrm{MPa}]$} & {$[\mathrm{MPa}]$} & {$[\mathrm{MPa}]$} & {$[\%]$} & {$[\%]$} \\
$73( \pm 1)$ & $510( \pm 5)$ & $580( \pm 5)$ & $780( \pm 10)$ & $16( \pm 2)$ & $22( \pm 2)$
\end{tabular}

E: elastic modulus; $\sigma_{\mathrm{Y} 0.2}: 0.2 \%$ yield stress; UTS: ultimate tensile strength; $\sigma_{\mathrm{F}}$ : true fracture stress; T.E.: total elongation; $\underline{\text { R.A.: reduction in area }}$

Table 1: Monotonic tensile properties of the Al-7075-T651 alloy. 

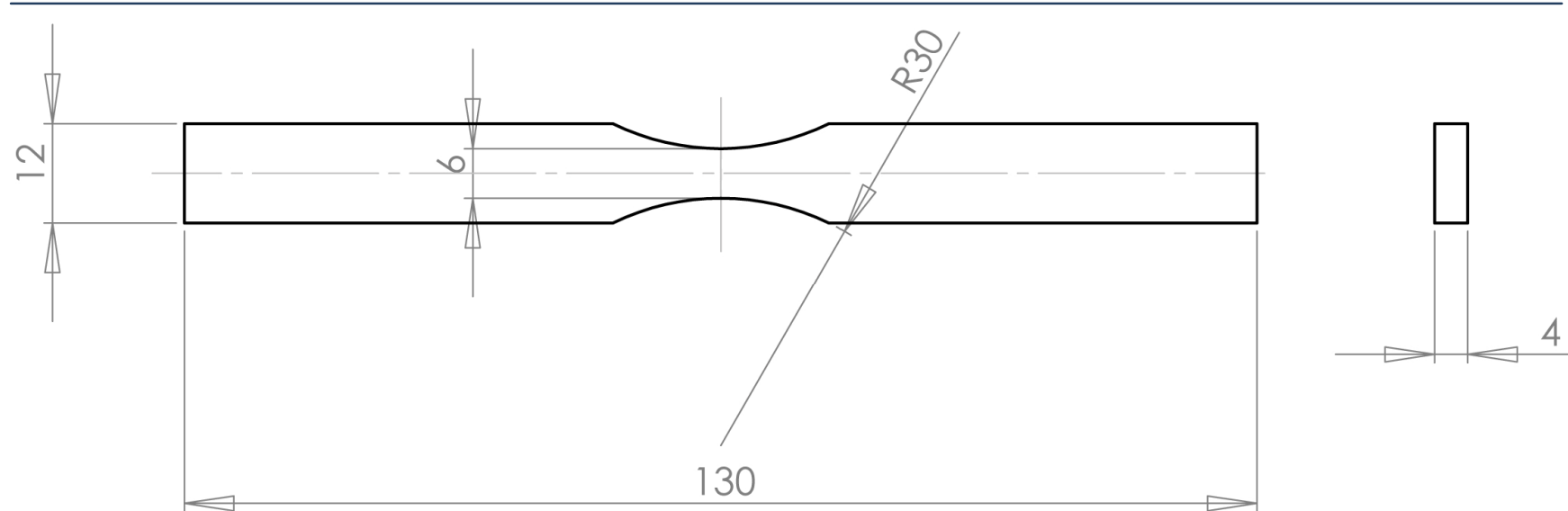

Figure 1: Geometry of the smooth hourglass specimen used in this study for bending fatigue tests. All dimensions are given in mm.

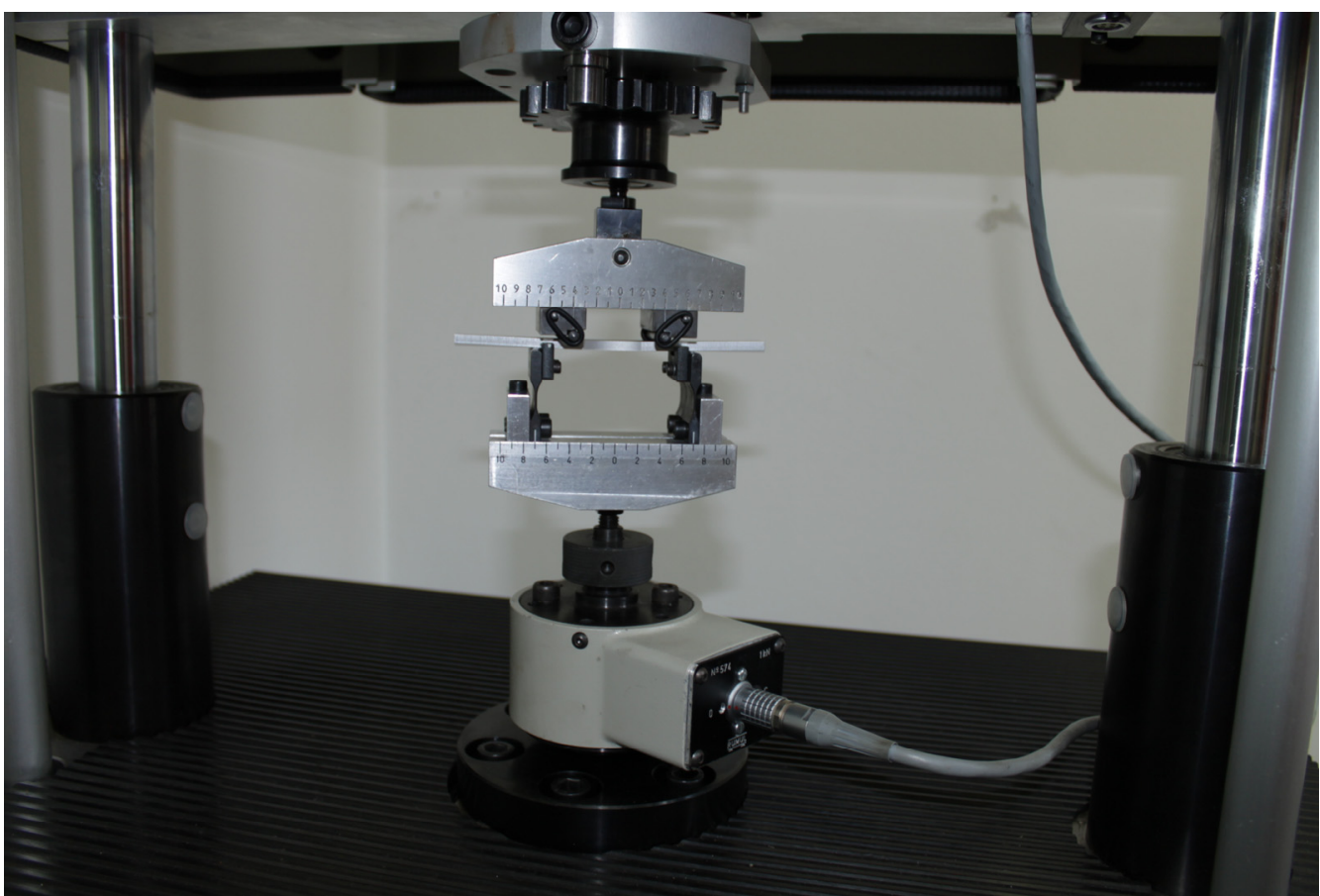

Figure 2: 4-point bending fatigue test apparatus used in the present study.

Part of the specimens was subjected to controlled shot peening: the parameters of the three peening treatments considered are summarized in Tab. 2. Each treatment was performed using non-metallic beads, which lend light alloys higher fatigue performance as compared with steel shots without introducing undesired galvanic effects [6]. The basic idea was to apply a widely used commercial peening treatment, termed Z425, employing beads of medium-small size (diameter $150 \mu \mathrm{m}$ ), which introduces some surface roughness and a deep cold worked layer (depth $\sim 100 \mu \mathrm{m}$ ), to explore an innovative peening treatment, called B120, with small ceramic beads leading to a gentle and superficial effect, and finally to investigate a fine particle shot peening treatment, termed V40, with very fine glass beads, which is known to greatly enhance the fatigue resistance of aluminium alloys [8].

In order to investigate the effect of the surface roughness induced by shot peening on the fatigue strength, three specimens previously subjected to the treatment B120 and V40 were then subjected to tribofinishing using a controlled vibrating tank with an aqueos medium containing high quality granulates and additives (mainyl surfactants). During the process, the specimen surface was periodically observed with an optical microscope to make sure that polishing is stopped just after removing all the dimples created by the shot peening treatments. A material surface layer of approximately $5 \div 10$ $\mu \mathrm{m}$ thickness was removed in this way. 


\begin{tabular}{|c|c|c|c|c|c|c|c|}
\hline Treatment & Material & $\begin{array}{c}\text { Bead size } \\
{[\mu \mathrm{m}]}\end{array}$ & $\begin{array}{c}\text { Bead hardness } \\
{\left[\mathrm{HV}_{1}\right]}\end{array}$ & $\begin{array}{c}\text { Bead } \\
\text { composition }\end{array}$ & $\begin{array}{c}\text { Almen } \\
\text { intensity }\end{array}$ & $\begin{array}{c}\text { Angle of } \\
\text { impingment }\end{array}$ & $\begin{array}{c}\text { Coverage } \\
{[\%]}\end{array}$ \\
\hline Z150 & Ceramic & $150 \div 210$ & \multirow{2}{*}{700} & $\mathrm{ZrO}_{2} 67 \%$ & $12 I$ & \multirow{3}{*}{$90^{\circ}$} & \multirow{3}{*}{100} \\
\hline B120 & Ceramic & $63 \div 125$ & & $\mathrm{SiO}_{2} 31 \%$ & $4.5 \mathrm{~N}$ & & \\
\hline V40 & Glass & $40 \div 70$ & 550 & $\begin{array}{c}\mathrm{SiO}_{2} 31 \% \\
\mathrm{Na}_{2} \mathrm{O} 14 \%\end{array}$ & $4.2 \mathrm{~N}$ & & \\
\hline
\end{tabular}

Table 2: Shot peening parameters.

Pulsating $(\mathrm{R}=0.05)$ load-controlled 4-point bending fatigue tests were carried out at room temperature air and at a nominal frequency of $110 \mathrm{~Hz}$ using a resonant testing machine Rumul Mikrotron $20 \mathrm{kN}$ equipped with a $1 \mathrm{kN}$ load cell (Fig. 2). Different stress levels corresponding to fatigue lives in the range between nearly $10^{5}$ and $10^{8}$ cycles were considered. Tests were terminated at $10^{8}$ cycles when no fracture occurred. The fatigue curves corresponding to $50 \%$ of failure probability, represented by the S-N curve:

$$
\sigma_{P 50}=\sigma_{0 P 50} \times N_{f}^{-\frac{1}{k}}
$$

were determined by fitting the $\log \left(N_{f}\right)$ vs. $\log (\sigma)$ results. The uncertainty range was assumed to be constant and approximated by its centroid value. As a representative value of the scatter, the following expression was used:

$$
T \sigma=1: \sigma_{P 90} / \sigma_{P 10}
$$

$P_{90}, P_{10}$ denote the $90 \%$ and $10 \%$ levels of failure probability, respectively.

The modifications of the surface layers of the shot peened samples were investigated through microhardness, surface roughness and residual stress profile measurements. To this regard, microhardness profiles were measured to characterize the material's work hardening. A confocal optical profilometer WLI Sensofar Plu Neox (plane surface spatial resolution of $0.31 \mu \mathrm{m}$, z-axial measurement resolution of $0.02 \mu \mathrm{m}$ ), was used to observe the samples surface. Three dimensional surface topography and roughness were evaluated.

The analysis of the residual stress field induced by the peening treatments was carried out by measuring the stress profile by XRD technique. For this purpose, an AST X-Stress 3000 X-Ray diffractometer (radiation Cr Ko, irradiated area 1 $\mathrm{mm}^{2}, \sin ^{2} \psi$ method, 11 diffraction angles $(2 \theta)$ scanned between $-45^{\circ}$ and $45^{\circ}$ ) was used. Calibration of the system was checked by collecting a diffraction pattern from a standard polycrystalline $\mathrm{Al}$ powder prior to conducting the experiment. The in-depth measurements were performed step-by-step removing a very thin layer of material using an electro-polishing device.

Both initial and stabilized residual stress fields were measured. For this purpose, measurements were performed on tested smooth specimens after failure in a region far enough from the fracture surface (about $2 \mathrm{~mm}$ ) so that the material rupture was supposed not to have altered the residual stress field [4]. Measurements were carried out on both specimen sides, subjected to tensile and compressive bending stresses, respectively.

\section{RESULTS AND DISCUSSION}

\section{Surface characteristics}

7 he effect on the surface roughness exerted by the shot peening treatments is quantified in Tab. 3, where the results of the optical profilometer measurements made on an assessment area $636 \times 477 \mu \mathrm{m}^{2}$ are summarized. It can be noted that the shot peening treatments increase the surface roughness with the respect to the as-received condition and that the most intense treatment Z150 results in a larger roughness increment with respect to the gentler processes B120 and V40. The tribofinishing is able to reduce the surface roughness of the peened samples below that of the virgin material. The as-received and the peened variants have a skewness close to zero, index of a symmetric height distribution (i.e. with as many peaks as valleys), while the tribofinished conditions have a negative skewness due to the fact that the surface asperities were removed by the polishing process. 


\begin{tabular}{cccccccccc}
\hline Condition & $\begin{array}{c}\mathbf{S}_{\mathbf{a}} \\
{[\mu \mathrm{m}]}\end{array}$ & $\begin{array}{c}\mathbf{S}_{\mathbf{q}} \\
{[\mu \mathrm{m}]}\end{array}$ & $\begin{array}{c}\mathbf{S}_{\mathbf{z}} \\
{[\mu \mathrm{m}]}\end{array}$ & $\mathbf{S}_{\mathbf{s k}}$ & $\mathbf{S}_{\mathbf{k u}}$ & $\begin{array}{c}\mathbf{S}_{\mathbf{d r}} \\
{[\%]}\end{array}$ & $\begin{array}{c}\mathbf{S}_{\mathbf{p k}} \\
{[\mu \mathrm{m}]}\end{array}$ & $\begin{array}{c}\mathbf{S}_{\mathbf{k}} \\
{[\mu \mathrm{m}]}\end{array}$ & $\begin{array}{c}\mathbf{S}_{\mathrm{vk}} \\
{[\mu \mathrm{m}]}\end{array}$ \\
As-received & 0.29 & 0.38 & 1.44 & 0.19 & 5.98 & 1.10 & 0.59 & 0.81 & 0.41 \\
Z150 & 3.79 & 4.83 & 21.29 & 0.29 & 8.60 & 40.61 & 8.09 & 11.56 & 3.56 \\
B120 & 1.24 & 1.54 & 7.12 & 0.14 & 3.03 & 6.07 & 1.75 & 3.96 & 1.42 \\
B120 trib. & 0.19 & 0.26 & 0.99 & -1.21 & 12.17 & 0.60 & 0.29 & 0.55 & 0.38 \\
V40 & 1.33 & 1.66 & 7.66 & -0.01 & 2.96 & 3.79 & 2.12 & 4.23 & 1.24 \\
V40 trib. & 0.17 & 0.23 & 0.87 & -1.30 & 12.52 & 0.61 & 0.28 & 0.49 & 0.33
\end{tabular}

$\mathrm{S}_{\mathrm{a}}$ : average roughness; $\mathrm{S}_{\mathrm{q}}$ : root mean square roughness; $\mathrm{S}_{\mathrm{z}}$ : maximum peak to valley height; $\mathrm{S}_{\mathrm{sk}}$ : skewness; $\mathrm{S}_{\mathrm{ku}}$ : kurtosis; $\underline{\mathrm{S}_{\mathrm{dr}}}$ : developed interfacial area ratio; $\mathrm{S}_{\mathrm{pk}}$ : reduced peak height; $\mathrm{S}_{\mathrm{k}}$ : core roughness depth; $\mathrm{S}_{\mathrm{vk}}$ : reduced valley depth

Table 3: 3D surface roughness properties.

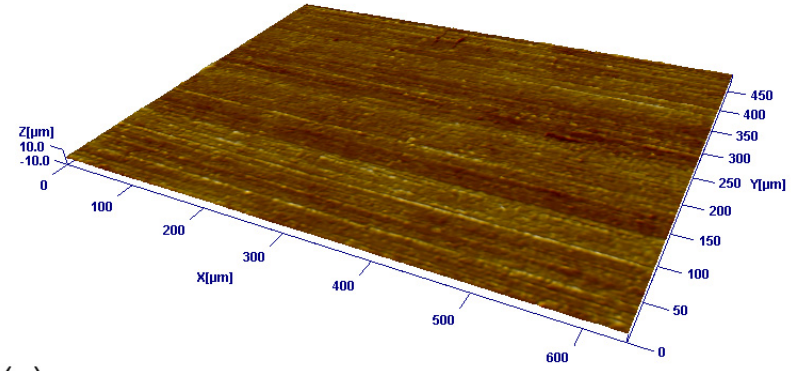

(a)

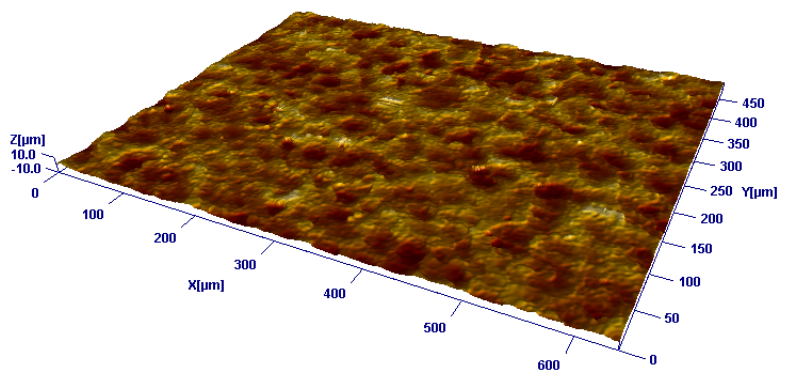

(c)

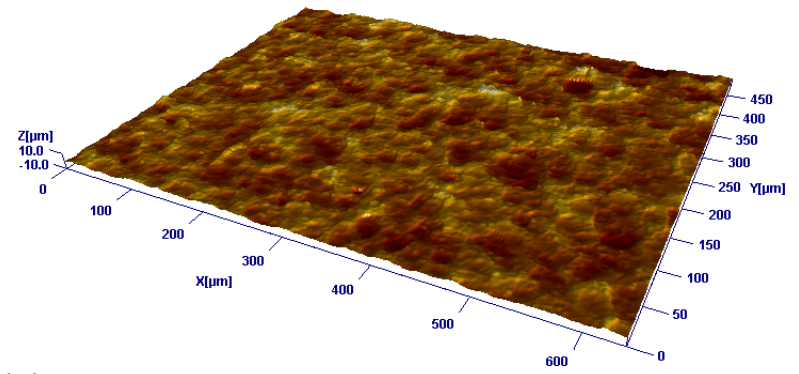

(e)

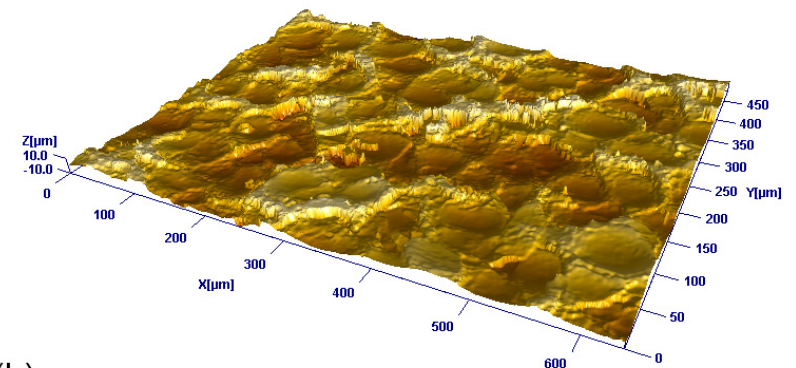

(b)

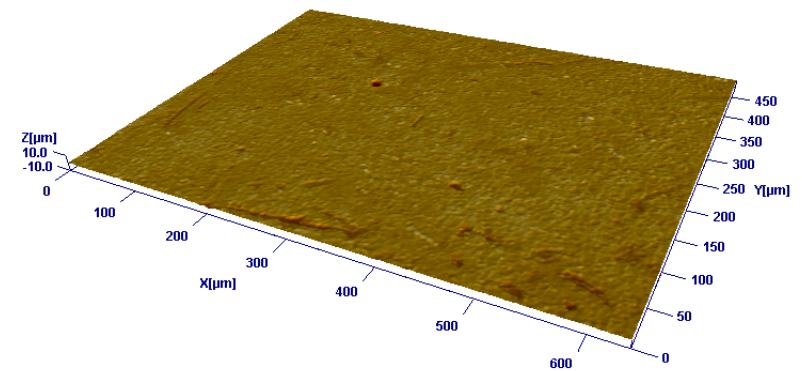

(d)

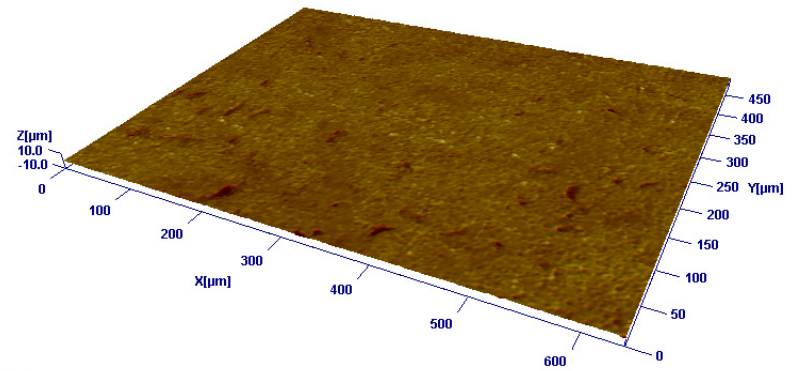

(f)

Figure 3: 4-point bending fatigue test apparatus used in the present study. Surface morphologies measured through optical profilometer. (a) as-received, (b) Z150 peened, (c) B120 peened, (d) B120 peened and tribofinished, (e) V40 peened, (f) V40 peened and tribofinished. The assessment area is $636 \times 477 \mu \mathrm{m}^{2}$.

The surface morphology of the virgin, Z150, B120, tribofinished B120, V40 and tribofinished V40 conditions is depicted in Fig. 3a-f, respectively. Notably, the surface morphology of the as-received condition is characterized by striations caused by the rolling process. The large beads used in the most intense peening treatment, i.e. Z150, created large and 
deep impact craters. Dimples of smaller size, typical of gentle superficial peening treatments, are visible on the surfaces of the B120 and V40 conditions. The superficial structure of impact craters is not visible on the tribofinished variants.

A comparison among the microhardness profiles measured for both the peening treatments and the as-received condition is illustrated in Fig. 4. Noticeable differences, which are directly correlated to the surface work hardening experienced by the material as well as to the depth of the surface layer interested by the plastic deformation, can be observed: B120 and V40 peening treatments are very superficial, the maximum hardness is within 10-20 $\mu \mathrm{m}$ from the surface, the depth of the surface layer interested by the plastic deformation is about $60 \mu \mathrm{m}$. The B120 treatment causes a more intense work hardening, and hence higher microhardness values, than the V40 treatment. The Z150 treatment induces a sub-superficial microhardness peak, where the Hertzian pressure is nearly maximal; the effect of shot peening vanishes at approximately $0.2 \mathrm{~mm}$ below the surface.

XRD measurements were carried out on the fatigue samples in order to characterize the residual stress field prior to fatigue testing. The obtained stress profiles are illustrated in Fig. 5. Two measurements per peening variant were performed in order to account for the variability in the residual stress field. The peening treatments B120 and V40 display a sub-superficial compressive residual stress peak located nearly $15 \mu \mathrm{m}$ below the surface and a depth of the surface layer interested by compressive residual stresses equal to about $50 \mu \mathrm{m}$. The B120 treatment induces higher residual stresses as compared with the V40 treatment. The most intense peening treatment Z150 is characterized by lower compressive surface residual stress, by higher sub-superficial compressive peak, and by deeper compressive residual stress profiles (about $90 \mu \mathrm{m}$ ) with respect to the gentler treatments. The repeatability of the residual stress measurements is very good within a depth of about $20 \mu \mathrm{m}$, where the fatigue response is mostly dictated [4], while it increases noticeably at higher depths, presumably due to the very elongated grain structure of the internal material layers that have not undergone recrystallization and hence grain refinement during shot peening.

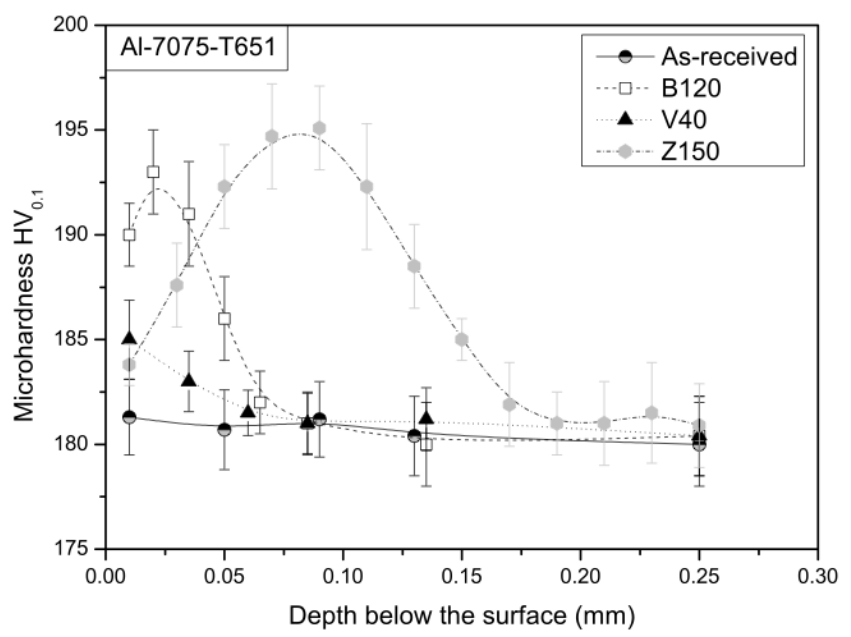

Figure 4: Microhardness profiles of the as-received and peened variants, obtained by averaging the results of three tests.

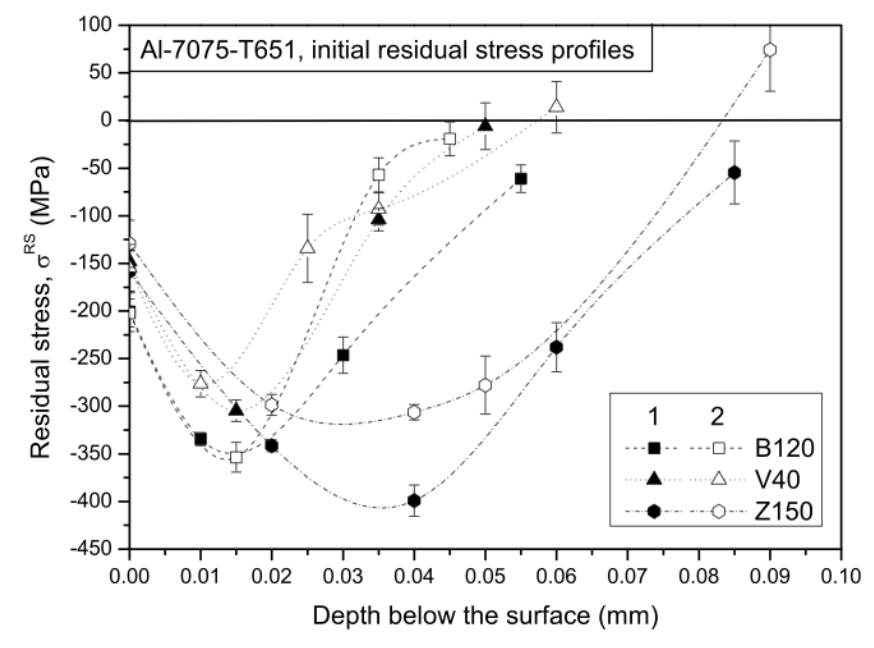

Figure 5: Initial residual stress profiles of the peened variants measured by XRD technique. Two measurements per peened variant were carried out in order to account for the variability in the residual stress field.

\section{Fatigue curves}

The results of the pulsating bending fatigue tests as well as the P50 fatigue lines are shown in Fig. 6 in the different material conditions considered and compared with those of the tests carried out on the two tribofinished variants. The parameters representing the fatigue curves corresponding to $50 \%$ of failure probability, according to Eq. (1) and the results scatter, expressed by Eq. (2) are listed in Tab. 4.

All the peening treatments considered were effective in prolonging the fatigue life of the material as well as in reducing the large scatter in fatigue results displayed by the virgin material. This improvement depends on the applied load, being more remarkable for load levels corresponding to shorter fatigue lives, leading however to higher values of the slope in the P50 fatigue line. Therefore, the increment in fatigue resistance due to shot peening steadily declines during fatigue life. The lightest V40 peening treatment, despite lower surface residual stresses and slightly higher roughness, is more effective in improving the plain fatigue resistance with respect to the B120 treatment, which, in turn, performs better than the most intense treatment Z150. Finally, it can be noted that the tribofinished samples displayed a fatigue performance 
significantly higher with respect to the corresponding peened condition: the increment in fatigue strength due tribofinishing is about 5\% for the V40 and even 20\% for the B120 condition. The fact that the tribofinishing increments the fatigue performes of V40 in less extent than B120 condition suggests the hypothesis that the particular surface morphology of the V40 condition, characterized by lower values of developed interfacial area ratio and the reduced valley depth, exerts a less detrimental effect on the fatigue response as compared with that exhibited by B120.

\begin{tabular}{|c|c|c|c|}
\hline Condition & $k$ & $\begin{array}{c}\sigma_{0 \mathrm{P} 50} \\
{[\mathrm{MPa}]}\end{array}$ & $\mathrm{T} \sigma$ \\
\hline As-received & 33 & 200 & $1: 1.22$ \\
\hline Z150 & 20 & 315 & 1:1.17 \\
\hline B120 & 12 & 555 & 1:1.19 \\
\hline V40 & 12 & 590 & 1:1.10 \\
\hline \multicolumn{4}{|c|}{ 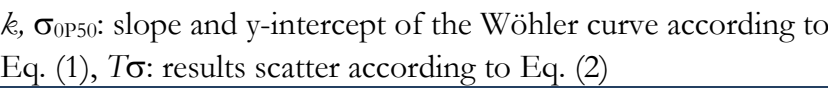 } \\
\hline
\end{tabular}

Table 4: Principal results of fatigue tests.

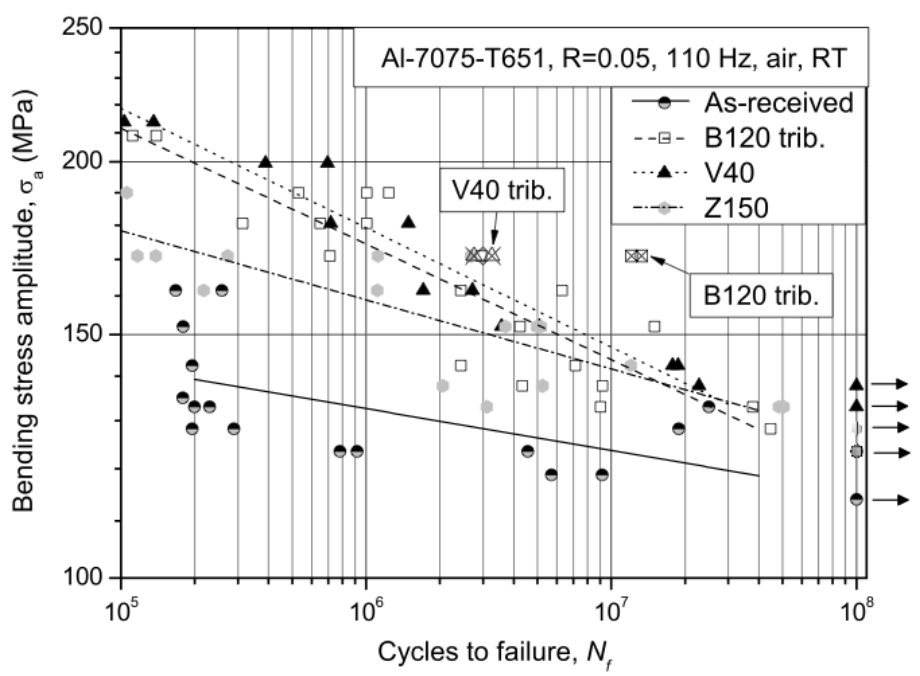

Figure 6: Pulsating bending fatigue curves of the as-received and peened conditions. Run-out tests are marked by arrows.

\section{Residual stress evolution during fatigue life}

Fig. 7, 8 and 9 illustrate the evolution of the residual stress field at two loading levels for the Z150, B120 and V40 treatment, respectively. Fig. $7 \mathrm{a}(8 \mathrm{a}, 9 \mathrm{a})$ and $7 \mathrm{~b}(8 \mathrm{~b}, 9 \mathrm{~b})$ refer to the specimen surface subjected to compressive and tensile bending stresses, respectively. It can be noted that some relaxation of the residual stress field occurred on the outer layer of the specimen side subjected to compressive bending stresses, the more pronounced the higher the load levels, especially in the B120 and Z150 conditions. Conversely, no appreciable relaxation occurred on the specimen side subjected to tensile bending stresses. This confirm the observations made in [4,5] that relaxation is more like a "quasistatic" effect, due to the achievement of the material's plasticization when the compressive bending stresses are superimposed to the compressive surface residuals stress field. Cyclic relaxation seems to be negligible, since the application of tens of millions fatigue cycles do not significantly alter the surface residual stress field on the tensioned side of the samples.

Fig. $10 \mathrm{a}$ and $\mathrm{b}$ illustrate the comparison between the initial (prior to tribofinishing) and the stabilized residual stress profiles for the tribofinished B120 and V40 variants, respectively. It can be noted that the material removal exposes on the surface the residual stress that was present at the corresponding depth prior to polishing. Moreover, tribofinishing caused some stress redistribution in the subsuperficial peak, while the depth of the surface layer interested by compressive residual stresses remained nearly unaffected. Residual stress profiles are very similar on the tensioned and the compressed side of the specimen, thus suggesting that no residual relaxation occurred at the investigated stress level. 


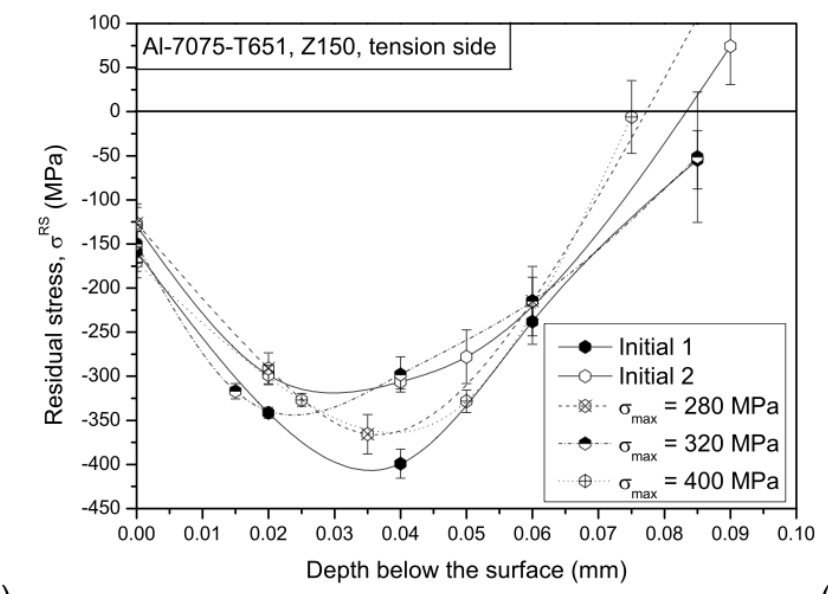

(a)

Figure 7: Evolution of the residual stress profile during fatigue life in samples subjected to Z150 treatment. (a) Tensioned, (b) compressed side. Specimen tested at $280(320,400)$ maximum stress MPa failed after $50.6 \times 10^{6}\left(5.1 \times 10^{6}, 106000\right)$ cycles.

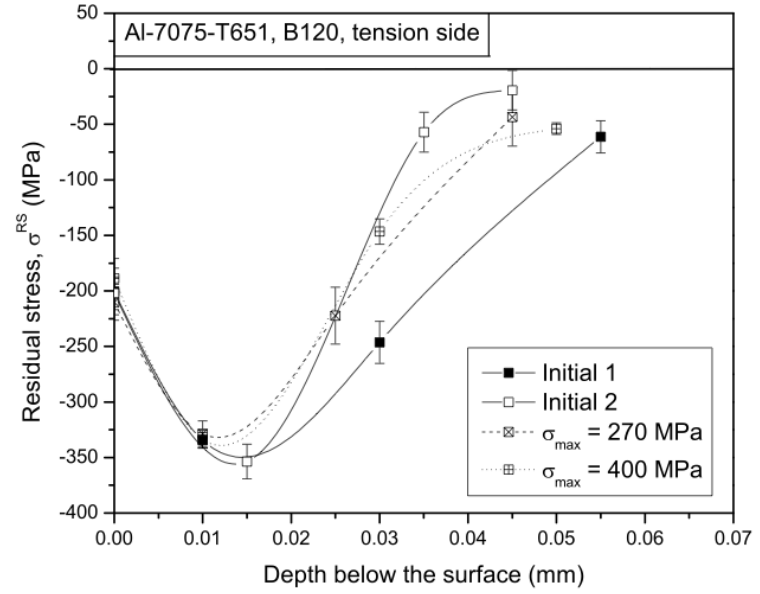

(a)

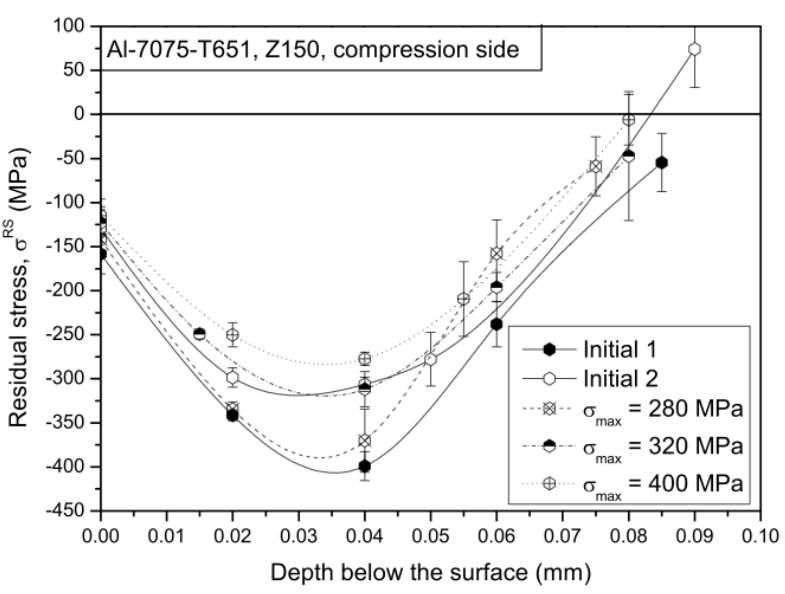

)

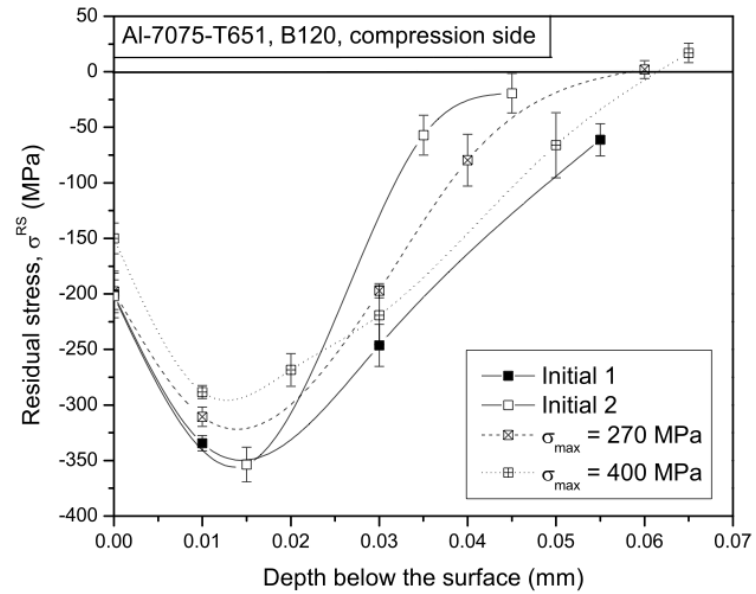

(b)

Figure 8: Evolution of the residual stress profile during fatigue life in samples subjected to B120 treatment. (a) Tensioned, (b) compressed side. Specimen tested at 270 (400) maximum stress MPa failed after 44.6×106 (530000) cycles.

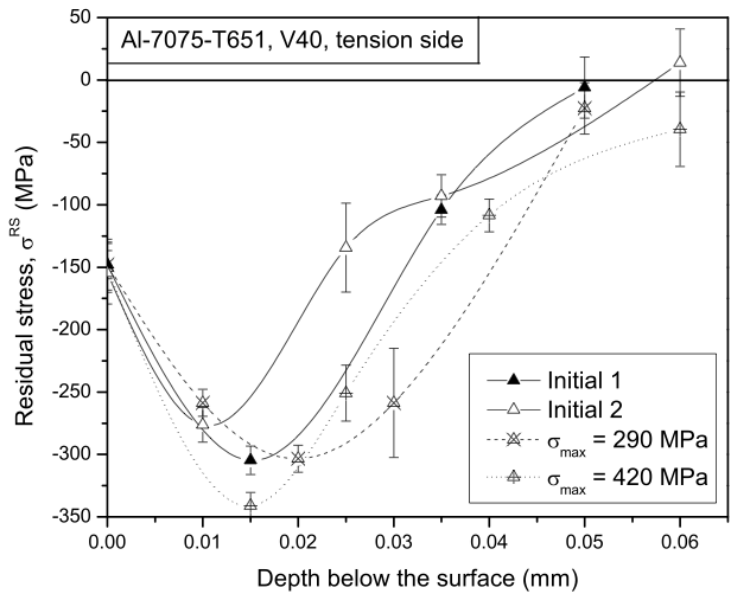

(a)

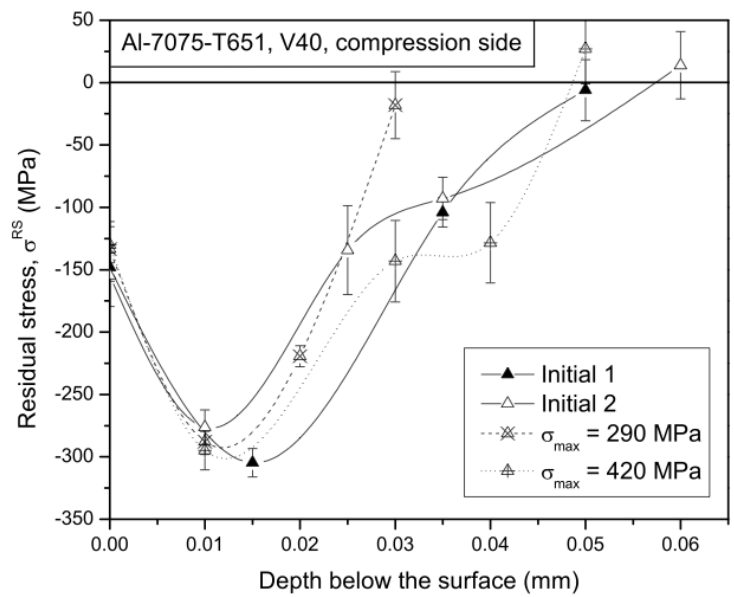

(b)

Figure 9: Evolution of the residual stress profile during fatigue life in samples subjected to V40 treatment. (a) Tensioned, (b) compressed side. Specimen tested at 290 (420) MPa maximum stress failed after $22.8 \times 10^{6}$ (390000) cycles. 


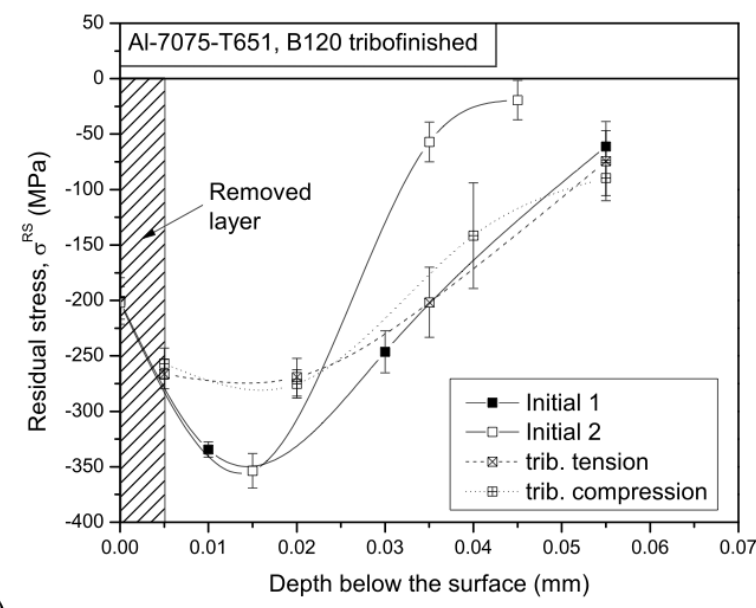

(a)

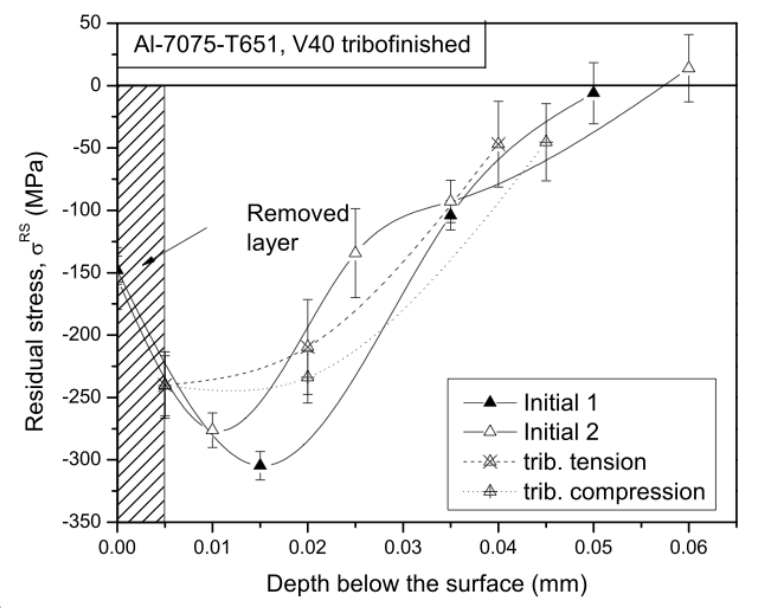

(b)

Figure 10: Evolution of the residual stress profile during fatigue life in tribofinished samples. Prior to tribofinishing the specimens were subjected (a) B120, (b) V40 peening treatment. Specimens were tested at $360 \mathrm{MPa}$ maximum stress and failed after $13.3 \times 10^{6}$ and $3.3 \times 10^{6}$ cycles, respectively.
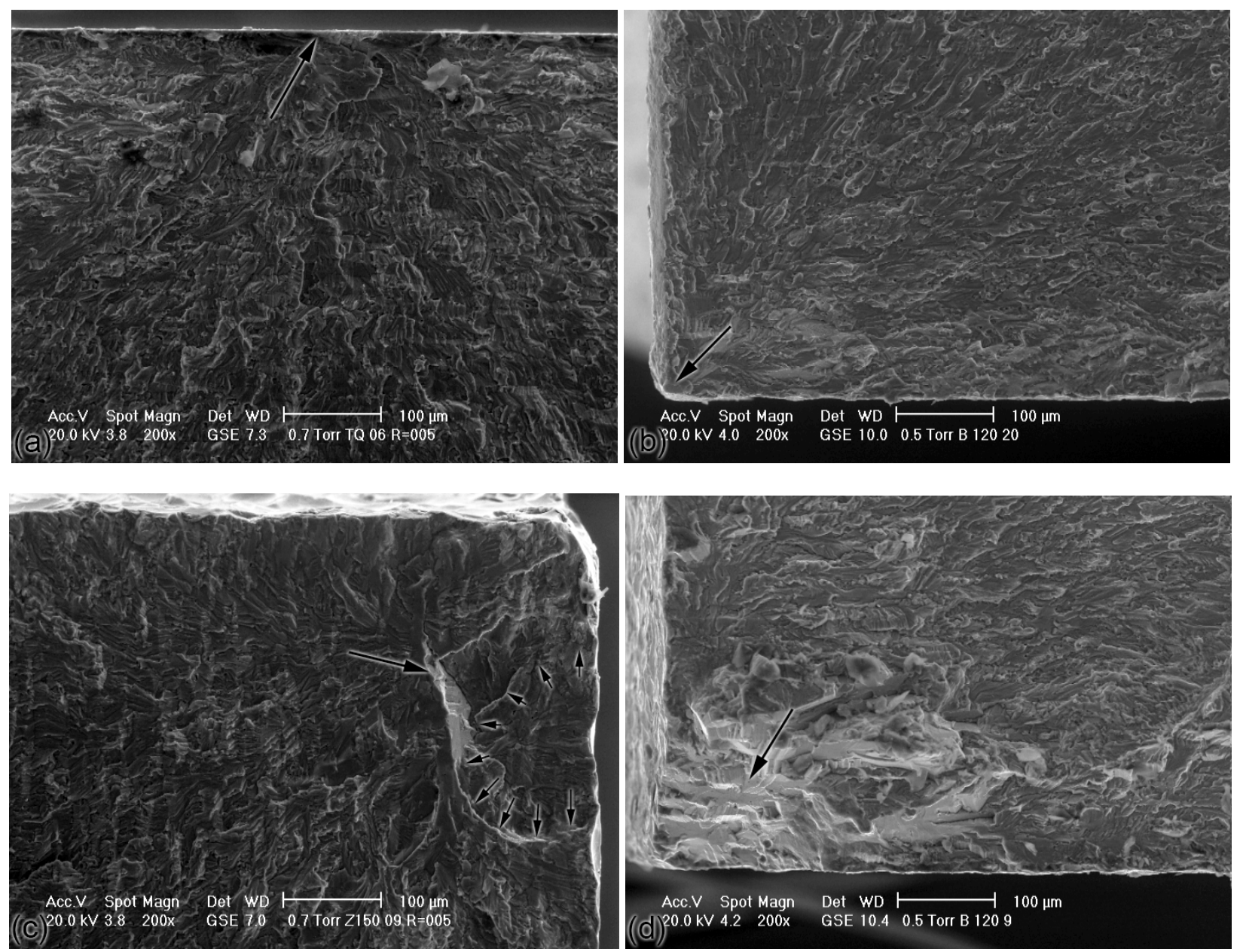

Figure 11: SEM micrographs of the fracture surfaces around the fatigue crack initiation sites. (a) as-received $\left(\sigma_{\mathrm{a}}=133 \mathrm{MPa}\right.$, $\left.\mathrm{N}_{\mathrm{f}}=25.0 \times 10^{6}\right)$, (b) B120 ( $\left.\sigma_{\mathrm{a}}=209 \mathrm{MPa}, \mathrm{N}_{\mathrm{f}}=139000\right)$, (c) Z150 $\left(\sigma_{\mathrm{a}}=133 \mathrm{MPa}, \mathrm{N}_{\mathrm{f}}=48.2 \times 10^{6}\right),(\mathrm{d}) \mathrm{B} 120\left(\sigma_{\mathrm{a}}=162 \mathrm{MPa}, \mathrm{N}_{\mathrm{f}}=\right.$ $\left.6.3 \times 10^{6}\right)$. 

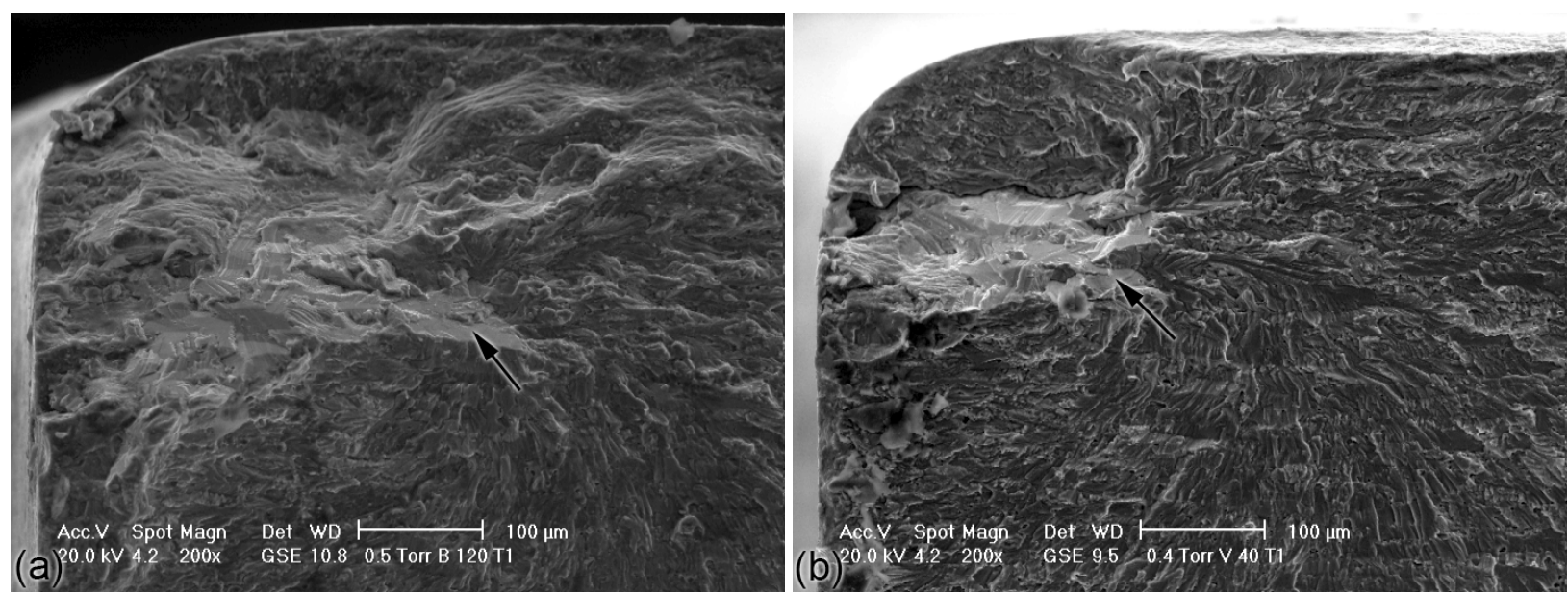

Figure 12: SEM micrographs of the fracture surfaces around the fatigue crack initiation sites in the tribofinished specimens. Prior to tribofinishing the specimens were subjected (a) B120, (b) V40 peening treatment. Specimens were tested at $\sigma_{\mathrm{a}}=171 \mathrm{MPa}$ and failed after $13.3 \times 10^{6}$ and $3.3 \times 10^{6}$ cycles, respectively.

\section{SEM analysis of fracture surfaces}

The SEM analysis of the fracture surfaces of the unpeened specimens revealed surface crack initiation troughout the entire fatigue life interval explored, even in the very high-cycle fatigue regime, as shown in Fig. 11a. In the peened variants, surface crack initation was found in the medium-cycle fatigue regime $\left(\mathrm{N}_{\mathrm{f}}<1 \times 10^{6}\right)$, as depicted in Fig. $11 \mathrm{~b}$ for the B120 condition. At longer fatigue lives $\left(\mathrm{N}_{\mathrm{f}}<2 \times 10^{6}\right)$, almost all crack initiation sites were found below the surface. Moreover, the fracture surfaces near the crack initiation sites show several crystallographic planes. This is frequently observed in $\mathrm{Al}$ alloys when fatigue tests are conducted under vacuum, and can be explained by the fact that the first propation stages of sub-superficial cracks occur at very low partial pressures of oxygen. In general, specimens that failed at a number of cycles less than that corresponding to P50 probabilty show a non-propagating crack at the surface, near the subsuperficial initiation site of the main crack, as shown exemplarily in Fig. 11c, while specimens that failed at a number of cycle significantly higher than that corresponding to P50 probabilty do not exhibit surface crack initiation, as depicted in Fig. 11d. Apparently, non propagating cracks, initiated on the surface because of the stress concentration effect exerted by surface roughness, and arrested by the closing effect exerted by compressive residual stresses, promote crack initiation in the underlying layer, thus leading to a shorter fatigue life.

Fig. 12a and b show the fracture surface of the tribonished B120 and V40 conditions, respectively. It can be noted that in both cases subsuperficial crack initation occurred, but the extension of crystallographic crack growth is larger in the B120 than in the V40 condition. Apparently, the deeper compressive residual stress profile of the B120 condition was more effective in retarding crack propagation up to the surface than that of the V40 variant.

\section{CONCLUSIONS}

$\mathrm{T}$ he plain fatigue strength of shot peened aluminium alloy Al-7075-T651 was experimentally investigated exploring fatigue lives comprised between $10^{5}$ and $10^{8}$ cycles. Experiments were conducted on specimens subjected to three different shot peening treatments. The surface morphology was characterized using an optical profilometer. To quantify the impact of surface induced by shot peening upon the fatigue response, some peened samples were tribofinished with the aim of eliminating surface roughness and preserving the surface residual stress field. XRD measurements were carried out to determine the initial and the stabilized residual stress field. The following conclusions can be drawn:

1. Residual stress relaxation occurs only when compressive bending stresses are superimposed to the surface compressive residual stress field.

2. The effect exerted by shot peening is a complicated interaction between residual stresses and surface roughness, greatly impacting the mechanism of fatigue crack initation and early propagation.

3. Shot peening conducted at low intensities with small beads is more effective in incrementing the fatigue resistance as compared to more intense treatments with larger shots, since it causes a lower roughnening of the surface and 
induces the maximum compressive residual stress as close as possible to the surface where crack initation is likely to occur. Fine shot particle causes a roughness increment comparable to that induced by peening treatment with small size, however its detrimental effect on the fatigue response seems to be lower.

4. In the very high cycle regime, the initation of the crack leading to final failure occurs in the subsuperficial layers and may be promoted by the presence of surface non-propagating cracks. By eliminating surface roughness through a tribofinishing treatment, the occurrence of surface crack initiation is suppressed, thus further incrementing the beneficial effect of shot peening. The extent of this additional improvement depends on the type of shot peening treatment, being more significant if the layer interested by compressive residual stresses is deeper.

\section{REFERENCES}

[1] M. Guagliano, L. Vergani, Eng. Fract. Mech., 71 (2004) 501.

[2] L. Wagner, Mat. Sci. Eng., A263 (1999) 210.

[3] R. C. McClung, Fatigue Fract. Engng. Mater. Struct., 30 (2007) 173.

[4] M. Benedetti, V. Fontanari, P. Scardi, C. L. A. Ricardo, M. Bandini, Int. J. Fatigue, 31 (2009) 1225

[5] M. Benedetti, V. Fontanari, B. D. Monelli, ASME J. Engng. Mat. Techn. , 132 (2010) 011012

[6] M. Benedetti, V. Fontanari, C. Santus, M. Bandini, Int. J. Fatigue, 32 (2010) 1600

[7] M. Benedetti, V. Fontanari, M. Bandini, Surf. Coat. Technol., in press

[8] K. Oguri, J. Mat. Proc. Technol., 211 (2011) 1395 